\title{
ALTERATIONS IN SPONTANEOUS ACTIVITY OF THE ISOLATED FROG SPINAL CORD IN CALCIUM-FREE ENVIRONMENT
}

\author{
Kiyoe KIM, Yoshihisa KUDO and Hideomi FUKUDA:

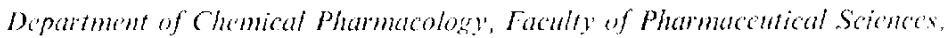 \\ Nagel'a City University, Mizuho-hu, Nagoya 467, fupan
}

Acepted Novmber 24, 1977

\begin{abstract}
Spontaneous clectrical activity of the isolated frog spinal cord was cxamined in Ca ${ }^{2+}$ free emvonment. Spontaneous discharges from the ventral root altered in four distinguishable steps. The first step was an immediate increase in the rate of spontaneous discharges and the sccond was a gradual decrease. The third was the occurrence of rhythmical bursts, and the last, the appearance of continuous firing. The rhythmical bursts could be depressed by the addition of matabolic inbibitors (ouabain or dinitrophenol in a concentration of $5.10^{-2} \mathrm{M}$ ) as well as of $\mathrm{Ca}$-chelating agents (EDTA or ECTA in a concentration of $10: \mathrm{M}$ ). Our results suggest that the oceurence of the rhythmical bursts requires a metabolic pumping process to redistribute $\mathrm{Na}^{+}$and $\mathrm{K}^{*}$ across the membrane and a small amount of $\mathrm{Ca}^{2+}$ for transmitter secretion.
\end{abstract}

It has been generally accepted that extracellular $\mathrm{Ca}^{2+}$ is indispensable for the process of transmitter release at the chemical synapses (1-5). In addition, extraceilular Ca ${ }^{2-}$ has been recognized as a stabilizer of excitable membrane, and depletion of the ion may lower the threshold $(6,7)$. Deficiency of $\mathrm{Ca}^{2+}$ may cause both the depression of spinal activity due to the inhibition of synaptic transmission and the excitation due to the lowered threshold of the membrane.

The purpose of the present study was to examine alterations in the spinal activity in a $\mathrm{Ca}^{2+}$-deficient environment. Although it is dificult to modify the ionic environment of the central nervous system, the adoption of the isolated, intraurterially perlused frog spinal cord (8) should help to overcome the problem, and make feasible investigations on the ionic mechanisms of excitability of the central nervous system.

\section{MATERIAIS AND MFTHODS}

The technique for preparing the isolated, perfused spinal cord preparation was essentially the same as that described by Matsuura et al. (8) and Kudo el al. (9).

The isolated spinal cord was perfused through the cannula inserted into the anterior spinal artery with amphibian Ringer's solution $\left(18_{-2} 2 \mathrm{C}\right.$ ) composed of (mM) $\mathrm{NiCl} 115$, $\mathrm{KCl} 2.7, \mathrm{CaCl}_{2} 1.8$ and glucose 5.5, buffered to $\mathrm{pH} 7.4-7.6$ with $\mathrm{NaHCO}_{3}$. Ca- free solution was prepared by the deletion of $\mathrm{CaCl}_{2}$ from normal Ringer's solution.

The 9 th or 10 th ventral root was mounted on a pair of silver-silver chloride electrodes

* Present Address: Deparment of Toxicology and Pharmacology, Faculty of Phamacentical Sciences, The University of Tokyo, Hoigo, Bunkyohu, Tokyo 113, Japan 
for recording. Spontaneous discharges were amplified with an $\mathrm{AC}$-amplifier (Nihonkohden AVB-2) and displayed on an oscilloscope (Nihonkohden VC-7). Discharges were then transformed into square waves and fed into an integrator, the output of which was recorded using a pen recorder (Nihonkohden WI-180). In some experiments, isolated spinal cordnerve-muscle preparation (10) was used. The isometric contractions of the muscle innervated by the spinal cord were recorded on a pen recorder through a force displacement transducer (Nihonkohden SB-1T) and an amplifier (Nihonkohden RP-2).

Spontaneous DC-shifts in the ventral and dorsal root were recorded by means of the sucrose-gap method $(9,11)$. Potential differences between the spinal cord and the peripheral stumps of ventral root or dorsal root were detected by calomel electrodes and then amplified by a DC-amplifier (San-ei Sokki 6L5), the output of which was recorded simultaneously by a two pen DC-recorder (Hitachi 056).

$\Lambda \mathrm{K}^{+}$-sensitive microelectrode was prepared by using $\mathrm{K}^{+}$-selective liquid ion-exchanger (Corning No. 477317) (12-14). The microelectrode and a reference electrode filled with $0.15 \mathrm{M} \mathrm{NaCl}$ were fixed on a supporting bar, and the two tips were assembled under microscopic obscrvation as near as possible. The paired electrodes were inserted into the lumbar region of the spinal cord in a depth of $1000 / \mathrm{m}$ from the ventral surface, where the pia mater had previously been partly removed to facilitate the insertion. The potential difference between the two electrodes was measured with a cathode follower differential amplifier (Nihonkohden MZ-3), and traced on a DC-recorder (Toa Electronics EPR 2000A). The $\mathrm{K}^{+}$ electrode was calibrated in Ringer's solution containing 2.0 to $6.0 \mathrm{mM} \mathrm{K} \mathrm{K}^{+}$.

Drugs were applied by replacing perfusing medium with the drug containing solution. The drugs used were ouabain (Merck), dinitrophenol (Wako Pure Chem.), cthyleneglycol bis-( $\beta$-aminocthylether)-N, $N^{\prime}$-tetraacetic acid (EGTA) (Wako Pure Chem.), ethylenediamine tetraacetic acid disodium salt (EDTA) (Wako Pure Chem.) and tetrodotoxin (Sankyo).

\section{RESULTS}

\section{Spontancous activity in $\mathrm{Ca}^{2+}$-free medium}

Spontaneous discharges from the ventral root could be observed within $1 \mathrm{hr}$ after the beginning of the perfusion as reported previously (15). When the bursts of discharges occurred irregularly and repeatedly, the normal Ringer's solution was replaced by $\mathrm{Ca}^{2+}$-free medium. Soon after the replacement, the rate of spontaneous discharges markedly increased. This increment was temporary and the discharges gradually decreased. When the exposure to $\mathrm{Ca}^{2+}$-free medium was continued, the bursts reappeared rhythmically as shown in Fig. 1. While the rhythmical bursts in $\mathrm{Ca}^{2+}$-free medium lasted, the irregular discharges began to interpose between the rhythmical bursts. About 60 min after the beginning of $\mathrm{Ca}^{2+}$-free medium perfusion, rhythmical bursts faded out, and only the continuous discharges remained.

Fig. 2 shows the spontaneous DC-potential changes detected between 9th ventral root (or dorsal root) and spinal cord. Imnediately after the perfusion with $\mathrm{Ca}^{2+}$-free medium, a marked depolarization was found in both roots. This depolarization was followed by 


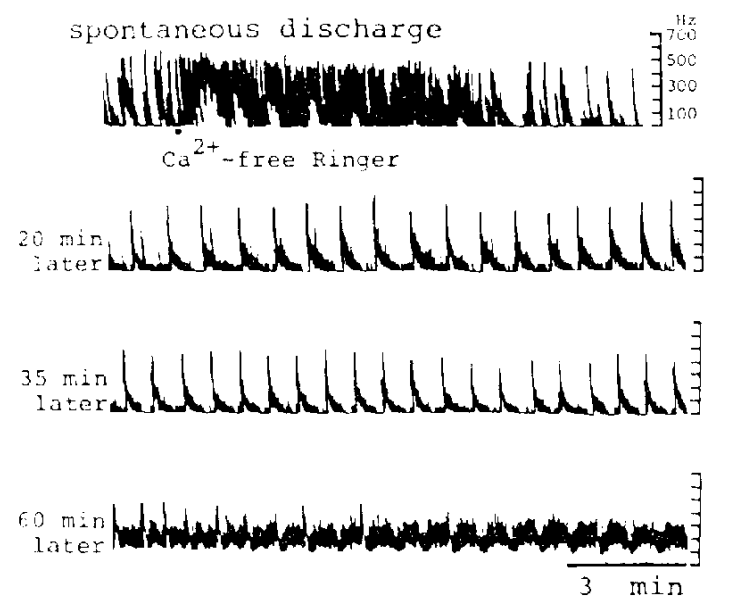

Fig. 1. Alterations in the spontancous discharges from the ventral root in $\mathrm{Ca}^{2}+$ free environment. Record shows the rate of spontaneous discharges measured by means of integrator. At the dot, the perfusion with $\mathrm{Ca}^{2+}$-free medium was started.

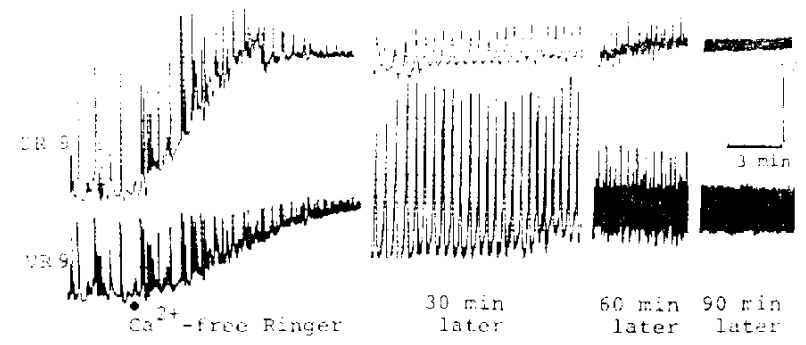

FIc. 2. Effects of $\mathrm{Ca}^{2+}$ removal on the patterns of ventral and dorsal root electrical activities (spontaneous DC-shifts) recorded simultaneously by means of the suerose-gap method.

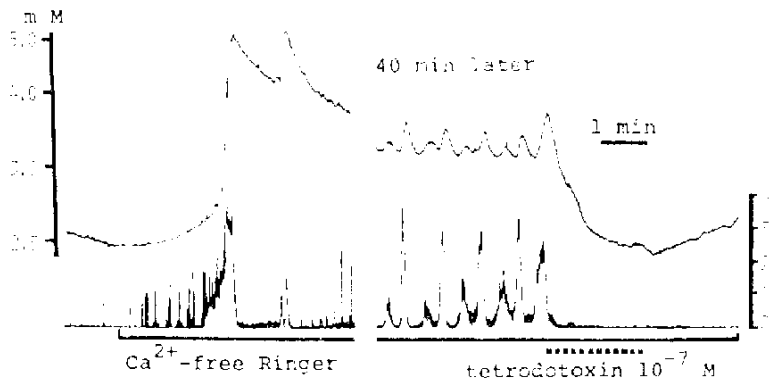

FIG. 3. Alterations in the extracellular $\mathrm{K}^{+}$-activity in $\mathrm{Ca}^{2+}$-free environment and the effects of tetrodotoxin $\left(10^{-7} \mathrm{M}\right)$. Upper trace: $\mathrm{K}^{+}$-activity measured by means of $\mathrm{K}^{+}$-selective mieroclectrode at a depth of $1000, \mu \mathrm{m}$ from the ventral surface of the lumbar region. Lower trace: the rate of spontaneous discharges from the ventral root measured by means of integrator. Solid line: time for $\mathrm{Ca}^{2+}$-free medium perfusion. Broken line: time for the application of tetrodotoxin. 
A
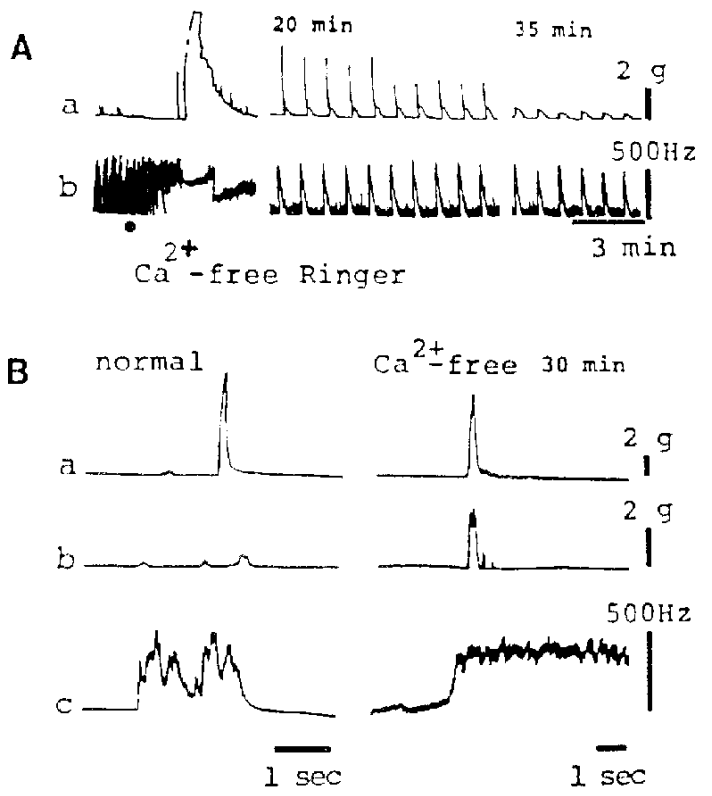

FIr. 4. Simultaneous recordings of spontaneous diseharges and muscle contractions in the isolated spinal cord-nerve-muscle preparation. A) (a) Spontancous contractions of $\mathrm{m}$. sartorius and $(b)$ the rate of spontaneous discharges from the 9th ventral root. B) (a) Spontaneous contractions of $\mathrm{m}$. gastrocnemius, (b) spontancous contractions of $\mathrm{m}$. tibilais anterior and (c) the rate of spontaneous discharges from the 9 th ventral root. $\mathrm{Ca}^{2}{ }^{2}$-free medium was applied only to the spinal cord through the anterior spinal artery.

the oscillatory potentials which obviously corresponded to the rhythmical bursts shown in Fig. 1. As shown in Fig. 3, the extracellular $\mathrm{K}^{+}$-activity measured by $\mathrm{K}^{+}$-sensitive microelectrode increased immediately after the exposure to $\mathrm{Ca}^{2+}$-free medium. Following the first increase in the activity, rhythmical fuctuation was observed. The increased $\mathrm{K}^{+}-$ activity as well as rhythmical fluctuation of the activity nearly ceased with the application of tetrodotoxin $\left(10^{--i} \mathrm{M}\right)$.

The isolated spinal cord-nerve-muscle preparation was employed to show how the muscles innervated by the spinal cord were influenced by the bursts from the ventral root. The sartorius muscle contracted only to the highly synchronized bursts in normal Ringer's solution, while the rhythmical contraction could be seen when the rhythmical bursts appeared in $\mathrm{Ca}^{2+}$-free medium (Fig. 4A). The spinal cord with both tibialis anterior and gastrocnemius muscles, which are antagonists to each other, was prepared. Under the perfusion of normal Ringer"s solution, the muscles showed spontaneous contraction, reciprocally. When the spinal cord was exposed to $\mathrm{Ca}^{2+}$ - -ree medium, the muscles contracted simultaneously. (Fig. 4B).

\section{Effects of drugs and divalcht cations on the rhythmicat bursts}

As shown in Fig. 5, rhythmical bursts observed after the perfusion with $\mathrm{Ca}^{2+}$-free solution were suppressed by the addition of $1.8 \mathrm{~mm}$ divalent cation $\left(\mathrm{Ca}^{2+}, \mathrm{Mg}^{2+}\right.$ or $\left.\mathrm{Mn}^{2+}\right)$. 
Soon after the removal of these cations from the perfusing medium, the rhythmical bursts reappeared.

By the application of EDTA $\left(10^{-3} \mathrm{M}\right)$ or EGTA $\left(10^{-3} \mathrm{M}\right)$, the rhythmical bursts disappeared immediately, and the continuous discharges could be seen. This result indicates

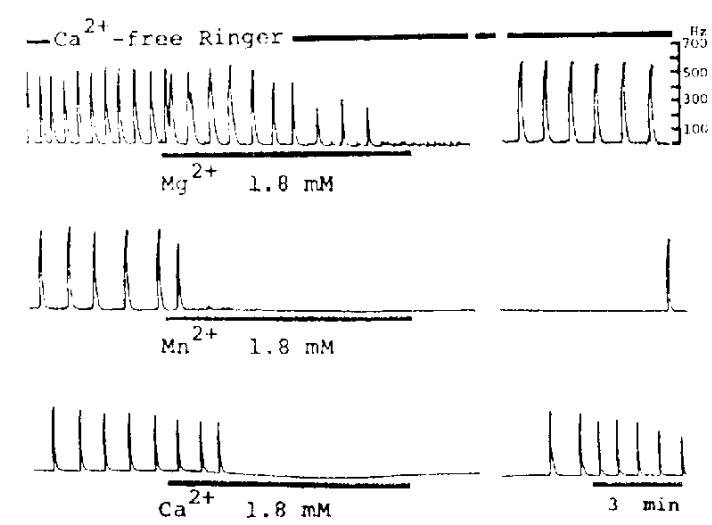

Fig. 5. Fiffects of divalent cations on the rhythmical bursts in $\mathrm{Ca}^{2}{ }^{2}$-free environment. Horizontal bars: time for divalent cation perfusion.

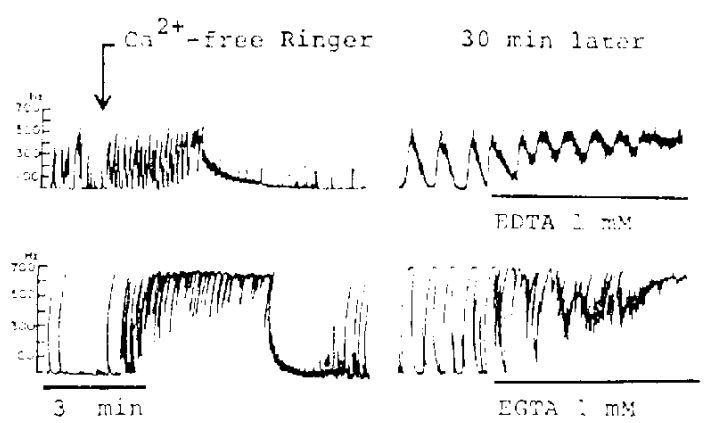

Гra. 6. Fifects of $\mathrm{Ca}^{3+}+$-chelating agents on the rhythmical bursts in $\mathrm{Ca}^{2}{ }^{2}$-free environment. Horizontal bars: time for drug perfusion.
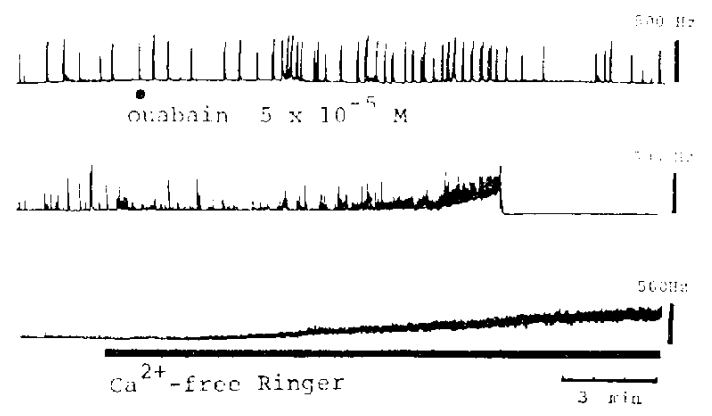

Fic. 7. Effects of oubain $(5.10 \% \mathrm{M})$ pretratment on the alturations in the spontancous discharges from the ventral root. At dot the application of ouban was started. Horizonal bar: time for Ca -free medim perfusion. 
that a small amount of $\mathrm{Ca}^{2+}$ is indispensable for the occurrence of oscillatory activity (Fig. 6 ).

After the pretreatment with ouabain $\left(5 \times 10^{-5} \mathrm{M}\right)$ for $30 \mathrm{~min}$, perfusion with $\mathrm{Ca}^{2-1}$-free solution did not result in initiation of rhythmical bursts. In this case, only continuous discharges were observed (Fig. 7). The same effect was obtained with dinitrophenol $\left(5 \times 10^{-5}\right.$ M)-pretreatment. Thus metabolic mechanisms probably participate in the occurrence of the rhythmical bursts in $\mathrm{Ca}^{2}$-free environment.

\section{DISCUSSION}

Spontancous discharges from the ventral root of the isolated spinal cord altered in four distinguishable steps after the exposure to $\mathrm{Ca}^{2+}$-free medium. The first step was an immediate increase in the rate of spontaneous discharges, the seeond a gradual decrease, the third occurrence of rhythmical bursts, and the last, the appearance of continuous firing.

Frankenhaeuser and Hodgkin (6) and Frankenhaeuser (7) have shown in squid giant axon and frog sciatic nerve that the reduction of the bound $\mathrm{Ca}^{2+}$ from the neuronal membrane during the perfusion with $\mathrm{Ca}^{2+}$-free medium produces an increase in the $\mathrm{Na}^{+}$influx, and depolarizes the excitable membranc. The first step with an immediate increase in the rate of the spontaneous discharges may depend on this change in the membrane permeability. The gradual decrease in spontaneous discharges observed as the second step can be partly ascribed to the depolarization block, as the membrane potential measured by the sucrose-gap method showed a full depolarization in this step.

The characteristic alterations in spontaneous discharges after $\mathrm{Ca}^{2+}$ frec medium perfusion were the occurrence of rhythmical bursts following a gradual decrease in the discharges. Rhythmical activity of the same type has been shown by Barker and Gainer (16) in the molluscan neurons exposed to $\mathrm{Ca}^{2+}$-free medium. These workers have suggested that the activity depends on the stimulatory effects on the intrinsic pace-making mechanism. In the rabbit atria, automaticity was observed after the treatment with $\mathrm{Ca}^{2+}$-chelating agents (17). There may be some neurons acting like molluscan pace-making cells in frog spinal cord, and such may contribute to the occurrence of synchronous burst. The synchronous contraction of the antagonistic muscles observed in the spinal cord-nerve-muscle preparation indicates that the inhibitory mechanisms lose their control on motoneurons which are highly excited in $\mathrm{Ca}^{2+}$-free medium. The rhythmical and synchronous bursts observed in the present study were depressed by the addition of metabolic inhibitors as well as by $\mathrm{Ca}^{2}$ chelating agents. The effects of metabolic inhibitors indicate that the occurrence of rhythmical bursts requires the metabolic pumping process to redistribute $\mathrm{Na}^{+}$and $\mathrm{K}^{+}$across the membrane. The extracellular $\mathbf{K}^{+}$activity measured by means of $\mathbf{K}^{+}$-sensitive microelectrode showed the parallel fluctuation with rhythmical burst activity in $\mathrm{Ca}^{2+}$-free medium. Tetrodotoxin reduced the extracellular $\mathrm{K}^{+}$activity and suppressed its fluctuation, suggesting that $\mathrm{K}^{+}$outflux has a linkage with tetrodotoxin-sensitive $\mathrm{Na}^{+}$influx in $\mathrm{Ca}^{2{ }^{2}}$-free environment.

The requirement of $\mathrm{Ca}^{2}$ for rhythmical activity was suggested by the results of prolonged exposure to $\mathrm{Ca}^{2+}$-free medium and of the addition of $\mathrm{Ca}^{2+}$-chelating agents, in which no rhythmical activity was observed. The occurrence of rhythmical bursts, therefore, must 
require a small amount of $\mathrm{Ca}^{2+}$ which is available for the secretion process of the transmitter to discharge the whole spinal neurons almost synchronously. The source of $\mathrm{Ca}^{2+}$ may be in the extracellular space, as has been suggested by Frankenhaeuser (7). The alternative possible source of the ion may be the intraceliular storage site such as mitochondria (18). The $\mathrm{Ca}$ ion in the intracellular storage site may be mobilized and utilized for the transmitter release during $\mathrm{Ca}^{2+}$-free perfusion. Further studies are in progress.

\section{REFERENCES}

1) KATZ, B. AND MILFDI, R.: The timing of calcium action during neuromuscular transmission. J. Physiol. 189, 535 544 (1967)

2) Kas7, B. AND Malt:1, R.: Ionic requirements of synaptic transmitter release. Nature 215, 651 (1967)

3) Katz, B. ANv Miledi, R.: The role of calcium in neuromuscular facilitation. $J$. Physiol. 195, $481-492(1968)$

4) Aufrbach, A.A.: Stricture and Function of Symoses, Edited by Pappas, G.D. And Purpura, D.P., p. 137, Raven Press, New York (1972)

5) Rubin, R.P.: Calcium and the Secretory Process, Plenum Press, New York (1974)

6) Frankinhablser, B. and Hodgikin, A.L.: The action of calcium on the electrical properties of squid axons. J. Physiol. 137, 218-244 (1957)

7) Frankfinhafuser, B.: The effect of calcium on the myelinated nerve fibre. J. Physiot. 137, $245-260(1957)$

8) Maisuura, S., Kawaguchi, S., Ichiki, M., Sorimachi, M., Kataoka, K. and Inouye, A.: Perfusion of frog's spinal cord as a convenient method for neuropharmacological studies. Europ, J. Pharmacol, 6, 13-16 (1969)

9) Kudo, Y., Amf, N., Goto, S. AND Fukuda, H.: The chloride-dependent depression by GABA in the frog spinal cord. Lurop. J. Pharmacol. 32, 251-259 (1975)

10) KuDo, Y., KIm, K. AND FrkUnA, H.: Dual effects of acetyleholine on the spontaneous activity in the isolated perfused spinal cord of the frog. Neuropharmacology 17, 29. 33 (1978)

11) Koketsi, K., Karczmar, A.G. and Kitamura, R.: Acetylcholine depolarization of the dorsal root nerve terminals in the amphibian spinal cord. Int. J. Neuropharmacol. 8 , $329-336(1969)$

12) KUdo, Y. AND FUKUdA, H.: Alteration of extracellular $\mathrm{K}^{-}$-activity indued by amino acids in the frog spinal cord. Japan. J. Pharmacol. 26, 385-387 (1976)

13) Walker, J.L. JR.: Ion specific liquid ion exchanger microelectrodes. Analyr. Chem. 43, 89A$93 \wedge(1971)$

14) Vyskočll, F. And Küíž, N.: Modinications of single and double-barrel potassium specific microelectrodes for physiological experiment. Pfiagers Arch. 337, 265-276 (1972)

15) KuDO, Y. ANI FuktDa, II.: Spontaneous electrical activity of the bulfrog spinal cord and susceptibility to some centrally acting drugs and amino acids. Japan. J. Pharmacol. 22, 731-733 (1972)

16) Barker, J.L. AND Gainer, H.: Bursting pacemaker potential activity in a normally silent neuron. Brain Res. 65, 516-520 (1974)

17) TODA, N.: Automaticity induced by $\mathrm{Ca}^{2+}$ chelating agents in isolated rablit left atria. Japan. J. Pharmacol. 24, 747-761 (1974)

18) Alnaes, E. AND RaHAmimofF, R.: On the role of mitochondria in transmitter release from motor nerve terminals. $J$. Physiol. 248, 285-306 (1975) 